\title{
EFEKTIVITAS PENGGUNAAN APLIKASI KONTRAKSI NYAMAN TERHADAP INTENSITAS NYERI PERSALINAN KALA I
}

\author{
Irfana Tri Wijayanti ${ }^{1}$, Sifa Altika ${ }^{2}$ \\ ${ }^{1}$ Dosen Program Studi Sarjana Kebidanan STIKes Bakti Utama Pati \\ Alamat Korespondensi: irfanawijayanti@gmail.com \\ ${ }^{2}$ Dosen Program Studi Sarjana Kebidanan STIKes Bakti Utama Pati \\ Alamat Korespondensi: sifa.altika@gmail.com
}

\begin{abstract}
Abstrak
Nyeri dalam persalinan merupakan suatu hal yang fisiologis, rasa nyeri ini disebabkan karena adanya kontraksi dan peregangan segmen bawah rahim dan serviks. Pada fase aktif persalinan, ketakutan primigravida lebih tinggi dibandingkan multigravida dan memiliki kontribusi terhadap tingkat nyeri serta durasi persalinan. Seiring dengan berkembangannya teknologi tepat guna dan semakin berkembangnya penerapan teknologi di dalam kehidupan, perlu diciptakan sebuah aplikasi kontraksi nyaman dikemas dalam sebuah aplikasi di android dibuat untuk membantu para ibu agar bisa merasakan nyamannya melahirkan dan mendapatkan pengalaman yang positif saat melahirkan. Tujuan penelitian ini adalah untuk mengetahui efektivitas penggunaan aplikasi kontraksi nyaman terhadap intensitas nyeri persalinan kala I di Kabupaten Kudus. Metode penelitian ini menggunakan eksperimen dengan rancangan one grup pre test dan post test. Sampel penelitian ini adalah $30 \mathrm{ibu}$ yang akan melahirkan. Instrumen penelitian menggunakan android yang didalamnya sudah aplikasi kontraksi nyaman dan lembar observasi nyeri. Uji paired T test menunjukkan hasil $\mathrm{p}$ value $=0,000<0,05$ yang artinya adanya keefektifan aplikasi kontraksi nyaman terhadap nyeri persalinan kala I sebelum dan sesudah pada kelompok intervensi. Nilai rata-rata sebelum Intervensi sebesar 5,93 \pm 1,70 dan sesudah penggunaan aplikasi rata-rata nyeri turun menjadi 1,45 $\pm 1,45$.
\end{abstract}

Kata Kunci: Aplikasi, persalinan, nyeri persalinan kala I

\begin{abstract}
Pain in childbirth is a physiological thing, this pain is caused by the contraction and stretching of the lower uterine and cervical segments. In the active phase of labor, the fear of primigravida is higher than that of multigravidas and contributes to the level of pain and duration of labor. Along with the development of appropriate technology and the growing application of technology in life, it is necessary to create a comfortable contraction application packaged in an application on Android made to help mothers feel the comfort of giving birth and get a positive experience during childbirth. The purpose of this study was to determine the effectiveness of using a comfortable contraction application on the intensity of the first stage labor pain in Kudus Regency. This research method used an experimental design with one group pre test and post test. The sample of this research is 30 mothers who will give birth. The research instrument uses an android which includes a comfortable contraction application and a pain observation sheet. The paired $\mathrm{T}$ test shows the results of $\mathrm{p}$ value $=0.000<0.05$, which means that there is the effectiveness of the application of comfortable contractions on the first stage labor pain before and after in the intervention group. The mean value before the intervention was $5.93 \pm 1.70$ and after using the application the average pain decreased to $1.45 \pm 1.45$.
\end{abstract}

Keywords : Application, childbirth, first stage labor pain

\section{PENDAHULUAN}

Nyeri persalinan merupakan fisiologis, rasa nyeri ini disebabkan karena adanya kontraksi dan peregangan segmen bawah rahim dan serviks. Menurut Alehagen (2001), pada fase aktif persalinan, ketakutan primigravida
(42,8\%) lebih tinggi dibandingkan multigravida $(29,5 \%)$ dan memiliki kontribusi terhadap tingkat nyeri serta durasi persalinan. Nyeri yang di alami selama persalinan dipengaruhi oleh beberapa faktor diantaranya usia, paritas, 
aktifitas fisik, psikologis, budaya, pengalaman dan pengetahuan tentang persalinan ${ }^{1}$.

Menurut penelitian Zephyrus (2010), Seorang wanita yang mengalami nyeri hebat pada kala I jika tidak dapat teratasi dengan baik, ini akan memicu stress. Bila wanita sudah mengalami stress akibat nyeri yang ia rasakan maka ini bisa memicu penekanan pengeluaran hormon oksitosin dalam tubuh, karena meningkatnya pengeluaran hormon progesterone yang menghambat terjadinya kontraksi berdampak melemahnya kontraksi uterus, kala I memanjang, gangguan sirkulasi darah ke uterus, fetal distress, hipokssia janin serta berdampak lebih buruk lagi seperti IUFD (Intara Unterin Fetal Dieth). Akibat yang ditimbulkan nyeri sangat buruk, yaitu meningkatkan angka morbiditas dan mortalitas AKI maupun AKB.

Hasil Riskesdas 2018 menunjukkan angka kematian ibu (AKI) di Propinsi Jawa Tengah berjumlah 421. Jika dilihat dari angka tersebut, AKI di tahun 2018 mengalami penurunan dari tahun 2017 berjumlah 475 dan tahun 2016 berjumlah $602^{2}$.

Salah satu upaya melakukan pertolongan persalinan tanpa rasa nyeri, dengan mendalami dan menerapkan metode-metode pengurangan rasa nyeri. Pengurangan nyeri persalinan terdapat 2 metode yaitu farmakologis dan nonfarmakologis ${ }^{3}$. Seiring dengan berkembangya teknologi dan penerapannya di dalam kehidupan, perlu diciptakan sebuah aplikasi kontraksi nyaman yang dikemas dalam sebuah aplikasi di Android. Isi aplikasi berupa sugesti atau afirmasi positif, musik, dan pencatatan kontraksi yang dibuat untuk membantu para ibu agar bisa merasakan nyaman dan mendapatkan pengalaman positif saat melahirkan ${ }^{4}$. Android merupakan sistem operasi mobile berbasis kernel Linux yang dikembangkan oleh Android Inc dan kemudian diakuisisi oleh Google ${ }^{5}$.

Aplikasi kontraksi nyaman dapat disebut sebagai salah satu pengobatan komplementer. Pengobatan komplementer di fasilitas pelayanan telah diatur pada peraturan menteri kesehatan Republik Indonesia Nomor 1109/Menkes/Per/IX/2007 pasal 3 yang berbunyi "pengobatan komplementer alternatif dilakukan sebagai upaya pelayanan yang berkesinambungan mulai dari peningkatan kesehatan (Promotif), pencegahan penyakit (preventif), penyembuhan penyakit (kuratif) dan atau pemulihan kesehatan (rehabilitatif). Hal ini didukung juga pada pasal 4 ayat 1 mengenai ruang lingkup pengobatan komplementer alternative terdiri dari: 1) intervensi tubuh dan pikiran (mind and body interventions), 2) sistem pelayan pengobatan alternative, 3) cara penyembuhan manual, 4) pengobatan farmakologi dan biologi, 5) diet dan nutrisi untuk pencegahan dan pengobatan, 6) cara lain dalam diagnose dan pengobatan ${ }^{6}$.

Data ibu yang bersalin di Klinik Lydia syfra pada tahun 2018 ada 144 ibu. Dari $10 \mathrm{ibu}$ hamil primigravida yang bersalin di klinik lydia syfra kudus didapatkan data bahwa 5 ibu mengalami nyeri persalinan berat, $3 \mathrm{ibu}$ mengalami nyeri persalinan sedang dan 2 ibu mengalami nyeri persalinan ringan. Rata-rata ibu mengatakan nyeri menyebabkan sulit konsentrasi menghadapi persalinan, mengatur nafas, merasa sesak nafas dan ibu trauma. Tujuan penelitian ini, untuk mengtahui efektifitas aplikasi kontraksi nyaman terhadap intensitas nyeri persalinan kala I. Penelitian ini sebagai salah satu pengobatan komplementer dalam pengurangan rasa nyeri persalinan kala I. 


\section{METODE PENELITIAN}

Jenis penelitian merupakan penelitian quasi eksperimen yang dilakukan di Kabupaten Kudus. Rancangan penelitian ini menggunakan pre and posttest only control group design. Pada design ini dilakukan tes kedua kelompok sebelum dan sesudah diberi pelakuan (intervention). Populasi penelitian ini adalah 40 Subyek penelitian. Sedangkan perhitungan sampelnya menggunakan rumus yang tertuang dalam buku Notoatmodjo (2012), sampelnya berjumlah 26 subyek penelitian (kelompok intervensi \& kontrol). Untuk mengantisipasi subyek penelitian drop out, ditambahkan 10\% dari sampel penelitian sekitar 3-4 subyek penelitian.

Data penelitian yang telah terkumpul kemudian ditabulasi ke dalam matriks pengumpulan data yang telah dibuat sebelumnya oleh peneliti dan kemudian dilakukan analisa data.

Uji korelasi yang digunakan dalam penelitian ini yaitu Paired T Test karena data berdistribusi normal. Penelitian ini telah mendapatkan surat keterangan laik etik dari Komisi Etik Penelitian Universitas Aisyiyah Yogyakarta No. 1717/KEPUNISA/X/2020.

\section{HASIL PENELITIAN}

Tabel 1 .

Karakteristik Subyek Penelitian

\begin{tabular}{lcccc}
\hline \multicolumn{1}{c}{$\begin{array}{c}\text { Karakteristik } \\
\text { Subyek Penelitian }\end{array}$} & $\mathrm{r}$ & $\%$ & $\mathrm{r}$ & \multicolumn{2}{c}{ Kelompok Intervensi } \\
\cline { 2 - 5 } Umur & $\mathrm{N}$ & & & \\
24-29 Tahun & 13 & $86,67 \%$ & 10 & $66,67 \%$ \\
30-35 Tahun & 2 & $13,33 \%$ & 5 & $33,33 \%$ \\
Pendidikan & & & & \\
SLTP & 0 & $0 \%$ & 1 & $6,67 \%$ \\
SLTA & 4 & $26,67 \%$ & 6 & $40 \%$ \\
PT & 11 & $73,33 \%$ & 8 & $53,33 \%$ \\
Pekerjaan & & & & \\
Swasta & 5 & $33,33 \%$ & 7 & $46,67 \%$ \\
Wiraswasta & 5 & $33,33 \%$ & 0 & $0 \%$ \\
Negeri & 2 & $13,34 \%$ & 1 & $6,66 \%$ \\
IRT & 3 & $20 \%$ & 7 & $46,67 \%$
\end{tabular}

Tabel 1 menunjukkan bahwa prevalensi umur ibu hamil mayoritas berumur 24-29 tahun pada kelompok intervensi sebanyak $13(86,67 \%)$ dan kelompok kontrol sebanyak 10 $(66,67 \%)$. Untuk pendidikan mayoraitas tamat perguruan tinggi pada kelompok intervensi sebanyak $11 \quad(73,33 \%)$, kelompok kontrol 8 (53,33\%). Untuk pekerjaan sebagian besar bekerja swasta dan wiraswasta pada kelompok intervensi sebanyak $5 \quad(33,33 \%)$ sedangkan pada kelompok kontrol sebanyak $7(46,67 \%)$.

Tabel 2 Gambaran Tingkat Nyeri Persalinan Kala I Sebelum dan Sesudah Pada 
Kelompok Intervensi (Penggunaan Aplikasi)

\begin{tabular}{llcccc}
\hline \multirow{2}{*}{ Tingkat Nyeri Persalinan Kala I } & \multicolumn{2}{c}{ Sebelum } & \multicolumn{2}{c}{ Sesudah } \\
& $\mathrm{n}$ & $\%$ & $\mathrm{~N}$ & $\%$ \\
\hline $0 \quad$ : Tidak Nyeri & - & - & - & - \\
1-3 : Nyeri Ringan & 2 & $46,67 \%$ & 6 & $40 \%$ \\
4-6 : Nyeri Sedang & 6 & $40 \%$ & 9 & $60 \%$ \\
10 : Nyeri Berat Terkontrol & 7 & $13,33 \%$ & - & - \\
\hline
\end{tabular}

Pada tabel 4.2 menunjukkan data sebelum penggunaan aplikasi tingkat nyeri persalinan kala I sebanyak 7 $(13,33 \%)$ berada pada skala nyeri berat bisa terkontrol. Namun setelah penggunaan aplikasi tingkat nyeri persalinan menunjukkan penurunan nyeri yaitu $9(60 \%)$ berada pada skala nyeri sedang.

Tabel 3

Gambaran Tingkat Nyeri Persalinan Kala I Sebelum dan Sesudah pada kelompok Kontrol (tidak Penggunaan Aplikasi)

\begin{tabular}{llcccc}
\hline \multicolumn{2}{r}{ Tingkat Nyeri Persalinan Kala I } & \multicolumn{2}{c}{ Sebelum } & \multicolumn{2}{c}{ Sesudah } \\
& n & $\%$ & $\mathrm{~N}$ & $\%$ \\
\hline $0 \quad$ : Tidak Nyeri & - & - & - & - \\
1-3 : Nyeri Ringan & - & - & - & - \\
4-6 : Nyeri Sedang & 6 & $40 \%$ & 5 & $33,33 \%$ \\
10 : Berat Tidak Terkontrol & 9 & $60 \%$ & 10 & $66,67 \%$ \\
\hline
\end{tabular}

Pada tabel 4.3 menunjukkan data pada kelompok kontrol, dikolom sebelum, tingkat nyeri persalinan kala I sebanyak $10(66,67 \%)$ berada pada skala nyeri berat bisa terkontrol. Namun pada kolom setelah, tingkat nyeri persalinan kala I menunjukkan penurunan nyeri yaitu $5(33,33 \%)$ berada pada skala nyeri sedang.

Tabel 4

Efektifitas Penggunaan Aplikasi Kontraksi Nyaman Terhadap Intensitas Nyeri Persalinan Kala I

\begin{tabular}{cccc}
\hline Variabel & N & $\begin{array}{r}\text { Mean } \pm \\
\text { SD }\end{array}$ & P value \\
& & $5,93 \pm 1,70$ & 0,000 \\
Sebelum & 15 & $1,45 \pm 1,45$ & \\
Sesudah & 15 & &
\end{tabular}

Pada tabel 4 nyeri persalinan kala I pada kelompok intervensi menggunakan uji Paired Test. Berdasarkan uji tersebut, menunjukkan nilai $\mathrm{p}$ value $=0,000<$ 0,05 yang artinya adanya keefektifan aplikasi kontraksi nyaman terhadap nyeri persalinan kala I sebelum dan sesudah pada kelompok intervensi. Nilai rata-rata sebelum Intervensi sebesar 5,93 $\pm 1,70$ dan sesudah penggunaan aplikasi rata-rata nyeri turun menjadi $1,45 \pm 1,45$. 
Tabel 5

Perbandingan Keefektifan Penggunaan Aplikasi Kontraksi Nyaman Terhadap Intensitas Nyeri Persalinan Kala I di Kabupaten Kudus

\begin{tabular}{ccccccc}
\hline Kelompok & Mean & SD & $\mathrm{t}$ & Mean Difference & Lower & Upper \\
\hline Intervensi & 3.40 & 1.45 & -5.325 & -2.733 & -3.7848 & -1.6818 \\
Kontrol & 6.13 & 1.35 & -5.325 & -2.733 & -3.7850 & -1.6816
\end{tabular}

Pada tabel 5 menunjukkan nilai $\mathrm{p}$ value $=0,000<0,05$ yang artinya ada perbedaan penurunan nyeri punggung pada ibu hamil trimester III sebelum dan sesudah pada kelompok intervensi dengan kelompok kontrol rata-rata

\section{PEMBAHASAN}

Hasil penelitian ini menunjukkan efektifitas penggunaaan aplikasi kontraksi normal terhadap intensitas nyeri persalinan kala I hal ini dapat dilihat dari $\mathrm{p}$ value $0,000<0,05$. Pada penilitian ini menggunakan aplikasi kontraksi nyaman dan menggunakan lembar observasi. Aplikasi yang telah dibuat diberi nama "IrFa Contraction". Isi dari aplikasi ini meliputi suara dan musik bertujuan untuk mensugesti ibu bersalin yang mengalami nyeri persalinan kala I. Musik yang lembut dan nyaman dapat mengalihkan rasa nyeri kearah yang lebih positif dan diserap melalui pendengaran (telinga), menuju ke otak bagian tengah (medula) dan menyetuh pikiran alam bawah sadar sehingga hormon endorphin dan ibu menjadi sangat rileks. Dan bisa dilihat melalui ciri-ciri secara fisik yaitu mata tenang, wajah rileks, nafas teratur, dan seluruh otot-otot tubuh menjadi rileks. Hal ini disebabkan oleh karena diberikannya tehnik relaksasi nafas dalam saat mendengarkan musik Musik dapat memberikan energi dan membawa perintah melalui irama sehingga musik dengan tempo yang tepat dapat membantu wanita mengatur penurunan tingkat nyeri persalinan kala I Sebesar 3,40. Hal ini membuktikan bahwa Aplikasi Kontrak Nyaman lebih efektif terhadap Intensitas nyeri dibandingkan dengan kelompok kontrol

pernapasannya selama nyeri persalinan (Di Fraco,1998 dalam Mander, 2004). Musik yang sering dipakai dalam distraksi nyeri adalah musik klasik. Beberapa penelitian telah membuktikan bahwa dengan mendengarkan musik terutama musik klasik dapat mengurangi kecemasan, tingkat ketegangan dan emosi atau nyeri fisik. Musik dapat digunakan untuk mengurangi stres penyebab rasa sakit dan mengendurkan otot - otot yang menegang sebagai reaksi terhadap rasa sakit tersebut. Musik juga mengubah persepsi waktu, yang menolong mengurangi rasa sakit yang diderita. (Kate dan Mucc, 2000, dalam Prasetya 2008) Hasil penelitian ini mendukung penelitian dari Husna (2010) menunjukkan bahwa terapi musik Instrumentalia efektif untuk menurunkan intensitas nyeri persalinan kala I aktif.

Hal ini sesuai dengan pernyataan dari Livingston (1985) dalam Mender (2004) neyatakan bahwa musik bisa digunakan dalam upaya meminimalkan nyeri persalinan, bagaimana kerjamusik membatu wanita menghadapi nyeri persalinannya terletak pada distraksinya dan kemampuannya untuk seseorang mengubah persepsi. Nyeri persalinan merupakan suatu kondisi yang fisiologis. 
Secara fisiologis nyeri persalinan mulai timbul pada persalinan kala I fase aktif, pada fase latem menjadi pembukaan sampai $3 \mathrm{~cm}$, fase aktif $4-10 \mathrm{~cm}$. Nyeri disebabkan oleh kontraksi uterus dan dilatasi servik semakin lama nyeri yang dirasakan akan bertambah kuat, puncak nyeri terjadi pada fase aktif. Intensitas nyeri selama persalinan mempengaruhi kondisi psikologis ibu, proses persalinan dan kesejahteraan janin (Potter dan Perry, 2006).

Hasil penelitian ini sependapat dengan penelitian Astrid Mulyani, dkk (2017) menyatakan terdapat pengaruh aplikasi kontraksi nyaman terhadap intensitas nyeri persalinan kala I pada ibu bersalin di wilayah kerja Puskesmas Cibeureum Kota Tasikmalaya. Adanya keefektifan penggunaan aplikasi kontraksi nyaman terhadap intensitas nyeri persalinan kala I. Ibu yang mengalami nyeri persalinana banyak yang masih merasakan takut, cemas, capek, tidak kuat sehingga menyebabkan nyeri persalinan yang hebat. Hasil penelitian ini sesuai dengan pernyataan dari Livingston, 1985 dalam Mander, (2004) bahwa musik bisa juga digunakan dalam upaya meminimalkan nyeri persalinan, bagaimana kerja musik membantu wanita menghadapi nyeri persalinannya terletak pada distraksinya dan kemampuannya untuk seseorang mengubah persepsi waktu. Nyeri persalinan merupakan suatu kondisi yang fisiologis. Secara fisiologi nyeri persalinan mulai timbul pada persalinan kala I fase laten dan fase aktif, pada fase laten terjadi pembukaan sampai $3 \mathrm{~cm}$, fase aktif terjadi pembukaan $4-10 \mathrm{~cm}$. Nyeri disebabkan oleh kontraksi uterus dan dilatasi servik, semakin lama nyeri yang dirasakan akan bertambah kuat, puncak nyeri terjadi pada fase aktif. Intensitas nyeri selama persalinan mempengaruhi kondisi psikologis ibu, proses persalinan, dan kesejahteraan janin (Potter dan Perry, 2006).
Beberapa kelebihan aplikasi kontraksi nyaman "IrFa Collection" bagi ibu hamil dan bersalin adalah bisa dipergunakan oleh ibu hamil yang akan mendekati taksiran persalinan yang mana aplikasi ini bisa mengetahui durasi, interval waktu yang tepat untuk pergi ke bidan atau ke klinik terdekat tanpa perlu lama lama di tempat bersalin. Selain itu pada sistem ini terdapat history sehingga dapat melihat kembali riwayat kontraksi. Aplikasi ini merupakan terobosan untuk mengalihkan rasa nyeri dan untuk lebih merilekskan dan membantu membuat nyaman ibu yang akan menghadapi proses persalinan

\section{DAFTAR PUSTAKA}

1. Astrid Mulyani. 2017. Pengaruh Aplikasi Kontraksi Nyaman Terhadap Perubahan Intensitas Nyeri Pada Persalinan Kala I Fase Aktif Di Wilayah Kerja Puskesmas Cibeureum Kota Tasikmalaya Tahun 2017. Diambil dari https://ejurnal.stikesbth.ac.id/index.php/P3M_JKBTH/a rticle/view/223. DOI: http://dx.doi.org/10.36465/jkbth.v1 $7 \mathrm{i} 2.223$

2. Datak. 2008. Manajaemen Nyeri Dalam Suatu Tatanan Tim Medis Multidisiplin Majalah Kedokteran Atma Jaya, Januari, Vol3, No. 1. EGC

3. Enterprise, Jubilee. 2010. Phonsel Android. Jakarta : Elex Media Komputindo

4. Hidayat Wicak. 2011. Buku Ajar Pintar Komputer Laptop Notebook \& tablet iPad \& Andriod Plus Internet. Jakarta Selatan : Media Kita

5. Husna, U. 2010, Pengaruh Terapi Musik Instrumental Terhadap Perbedaan Intensitas Nyeri Persalinan Fase Aktif Kala 1 Pada Primigravida Di Wilayah Kerja 
Puskesmas Dangung Dari : http://Tepositoty.Unand.ac.id

6. Judha M., Sudarti, Fauziah A. 2012. Teori Pengukuran Nyeri dan Nyeri Persalinan. Yogyakarta: Nuha Medika

7. Mander, Rosemary. 2004, Nyeri Persalinan, Jakarta: EGC.

8. Notoatmodjo, S. 2015. Metode Penelitian Kesehatan. Jakarta: RinekaCipta

9. Potter, P. A., \& perry, A.G. 2006, Buku Ajar Fundamental Keperawatan, Jakarta : EGC
10. Smeltzer, S.C BareB.G. 2002, Buku Ajar Keperawatan MedikalBedah.Jakarta:EGC.

11. Wiknjosastro, H. 2010. Ilmu Kebidanan Jakarta: Yayasan Bina Pustaka Sarwono Prawirohardjo

12. Varney, H. 2007. Buku Ajar Asuhan Kebidanan Edisi 4. Jakarta: EGC

13. Yuliatun L. 2008. Penanganan Nyeri Persalinan Non Farmakologi. Malang: Banyu Media Publishing. 